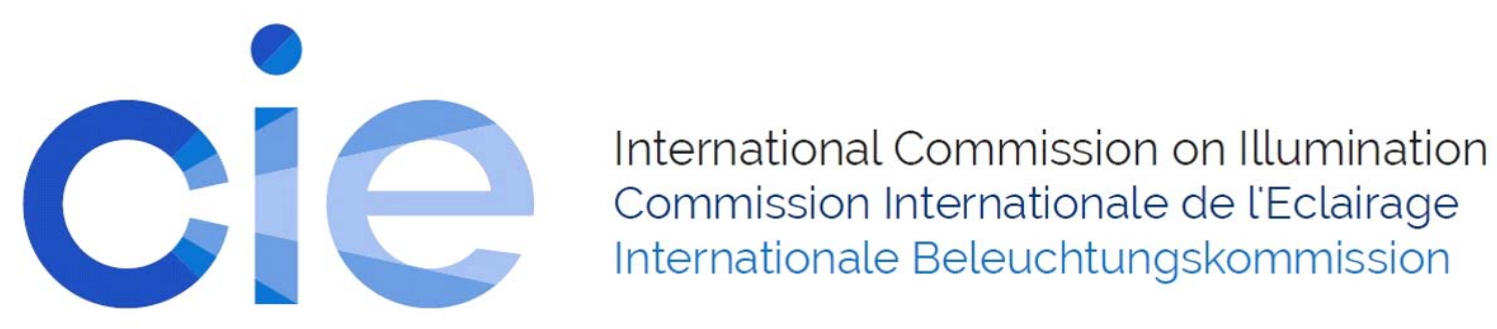

P0148

\title{
A STUDY ON THE APPROPRIATE CONTRAST OF LUMINANCE BETWEEN PAINTINGS AND WALL SURFACES IN MUSEUMS \\ Yukino Shimizu et al.
}

DOI 10.25039/x46.2019.PO148

from

CIE x046:2019

Proceedings

of the

29th CIE SESSION

Washington D.C., USA, June 14 - 22, 2019

(DOI 10.25039/x46.2019)

The paper has been presented at the 29th CIE Session, Washington D.C., USA, June 14-22, 2019. It has not been peer-reviewed by CIE.

(C) CIE 2019

All rights reserved. Unless otherwise specified, no part of this publication may be reproduced or utilized in any form or by any means, electronic or mechanical, including photocopying and microfilm, without permission in writing from CIE Central Bureau at the address below. Any mention of organizations or products does not imply endorsement by the CIE.

This paper is made available open access for individual use. However, in all other cases all rights are reserved unless explicit permission is sought from and given by the CIE.

CIE Central Bureau

Babenbergerstrasse 9

A-1010 Vienna

Austria

Tel.: +431714 3187

e-mail: ciecb@cie.co.at

www.cie.co.at 


\title{
A STUDY ON THE APPROPRIATE CONTRAST OF LUMINANCE BETWEEN PAINTINGS AND WALL SURFACES IN MUSEUMS
}

\author{
Shimizu, Y. ${ }^{1}$, Muto, S. ${ }^{1}$, Yoshizawa, N. ${ }^{1}$ \\ 1 Tokyo University of Science, Chiba, JAPAN \\ 7118535@ed.tus.ac.jp
}

DOI 10.25039/x46.2019.PO148

\begin{abstract}
Current guidelines for the museum lighting prescribe the appropriate range of illuminance on the exhibits as shown in the CIE standard to reduce the damage to paintings while balancing the conservation and exhibition. There is a possibility that the brightness of the paintings on the wall is determined by the luminance distribution, thus it is desirable to execute luminance-based design even for the museum lighting. The purpose of this study is to achieve the best light environment with the minimum illuminance on paintings by controlling the contrast of luminance between paintings and wall surfaces. We have conducted painting assessment experiments in an experimental room. Results showed that Quality Evaluation Factor could be ensured even though the illuminance on the paintings were $1001 x$, provided that the luminance ratio was sufficiently high, whereas Discrimination Factor was always highly evaluated when the painting illuminance was $2001 x$.
\end{abstract}

Keywords: Museum lighting, Luminance-based design, Luminance ratio, Paintings,

\section{Backgrounds and Purposes}

Current guidelines for the museum lighting prescribe the appropriate range of illuminance on the exhibits. The CIE standard (CIE 157:2004) categorizes the responsiveness of the exhibited material to light and sets a limit on the Illuminance for each category. This recommended value is important to reduce the damage to paintings while balancing the conservation and exhibition. On the other hand, the brightness of the paintings on the wall is determined by the luminance distribution, thus it is desirable to execute luminance-based design even for the museum lighting. In recent years, with the development of the simulation technologies and low-priced luminance measurement systems, it could be said that it has gradually become possible to introduce a new design method even in museums. By considering the appropriate luminance contrast by which the painting appears brighter, there is a possibility that illuminance on the painting could be reduced and lower the damage to the painting. The purpose of this study is to achieve the best light environment with the minimum illuminance on paintings by controlling the contrast of luminance between paintings and wall surfaces in museums.

\section{Luminance ratio}

In this study, luminance ratio is calculated by dividing the average luminance of the painting by the luminance on the surrounding wall. Figure 1 shows the surrounding area which is said to be the field of stable attention. Luminance is measured using a CCD camera with a fisheye lens.

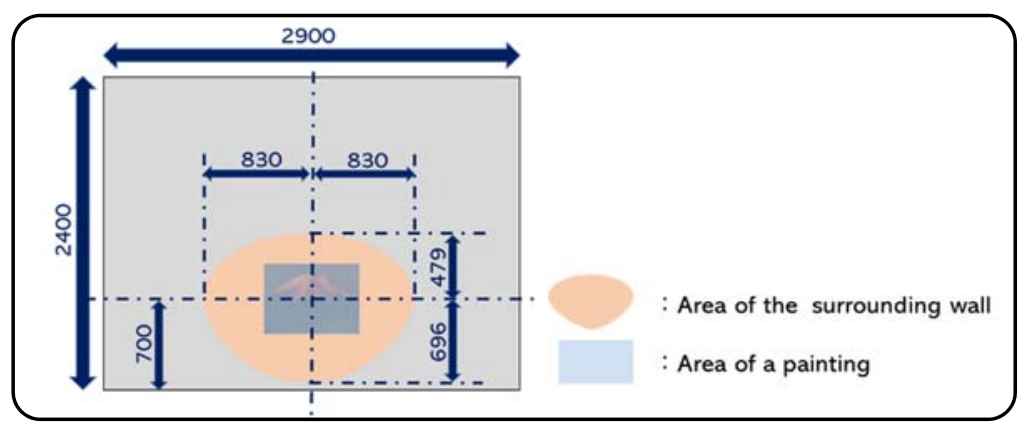

Figure 1 - The positional relation between a painting and a surrounding wall 


\section{Experiment Methods}

In this research, a subjective experiment was conducted, and the subjects evaluated the appearance and brightness of oil paintings and the appropriateness of the luminance ratio.

The experimental room as shown in Figure 2 was $2900 \mathrm{~mm}$ in width, $3000 \mathrm{~mm}$ in depth and $2400 \mathrm{~mm}$ in height. Buffering space for ambient lighting was made in the location of $1900 \mathrm{~mm}$ in height behind the subject. Lightness of the ceiling, the walls and the floor were N9.5 (White). Walls on which paintings are displayed with three kind of lightness, N2, N5 and N8, were prepared in this experiment to verify the effect of the lightness of the background.

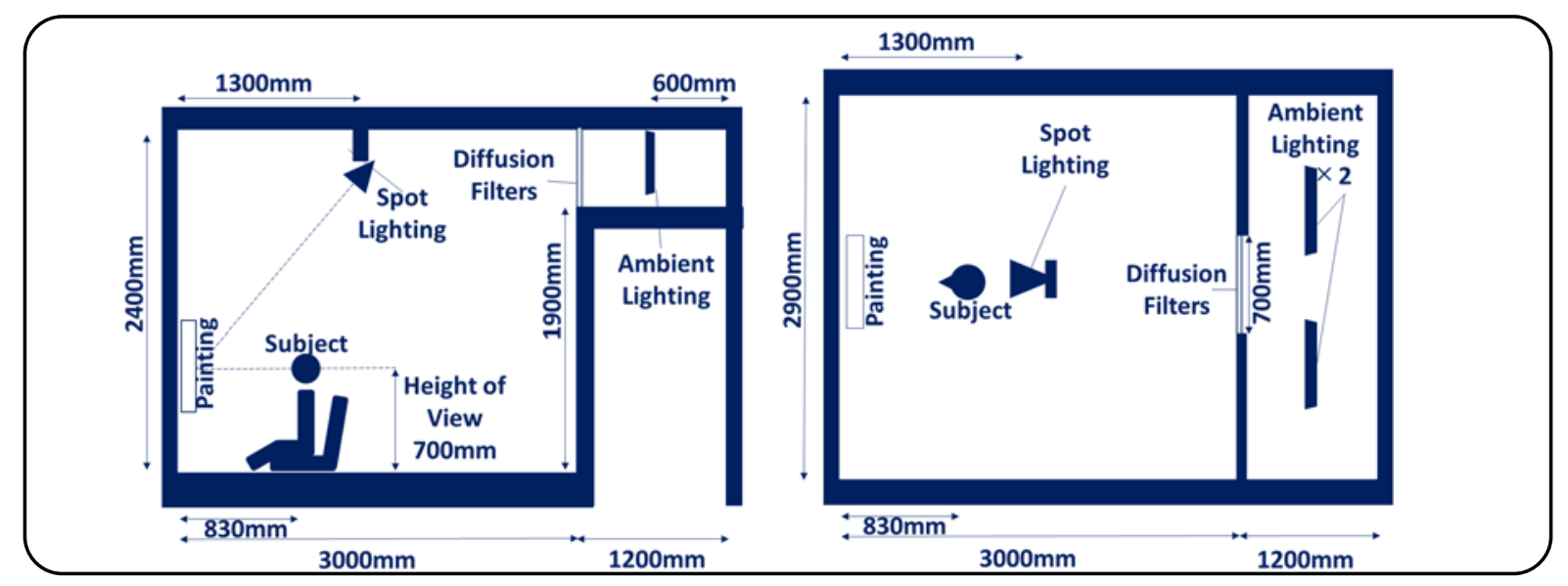

Figure 2 -Section (left), Plan (right) of the experimental room

Four oil paintings as shown in Figure 3 were used in this experiment. Painting $A$ was "Red Mt.Fuji" drawn by Yasushi Nakao and had a reflectance of the lowest 7.3\%, Painting B was a replica of "La Transfiguration" drawn by Peter Paul Rubens and had a reflectance of $15.7 \%$, Painting C was a colourful scenery picture named "Lake Como" drawn by Tadashi Orita and had a reflectance of $26.7 \%$, and Painting D named "The northern Japanese alps" drawn by Kazuo Furuichi was the image of snow mountains in Japan and had a reflectance of the highest $37.2 \%$. The reflectance of the painting was determined as follows; the painting surface was divided into 40 parts, and the reflectance of 40 parts was measured and their arithmetic mean was calculated. The size of all the paintings was $530 \mathrm{~mm}$ wide $\times 455 \mathrm{~mm}$ height.

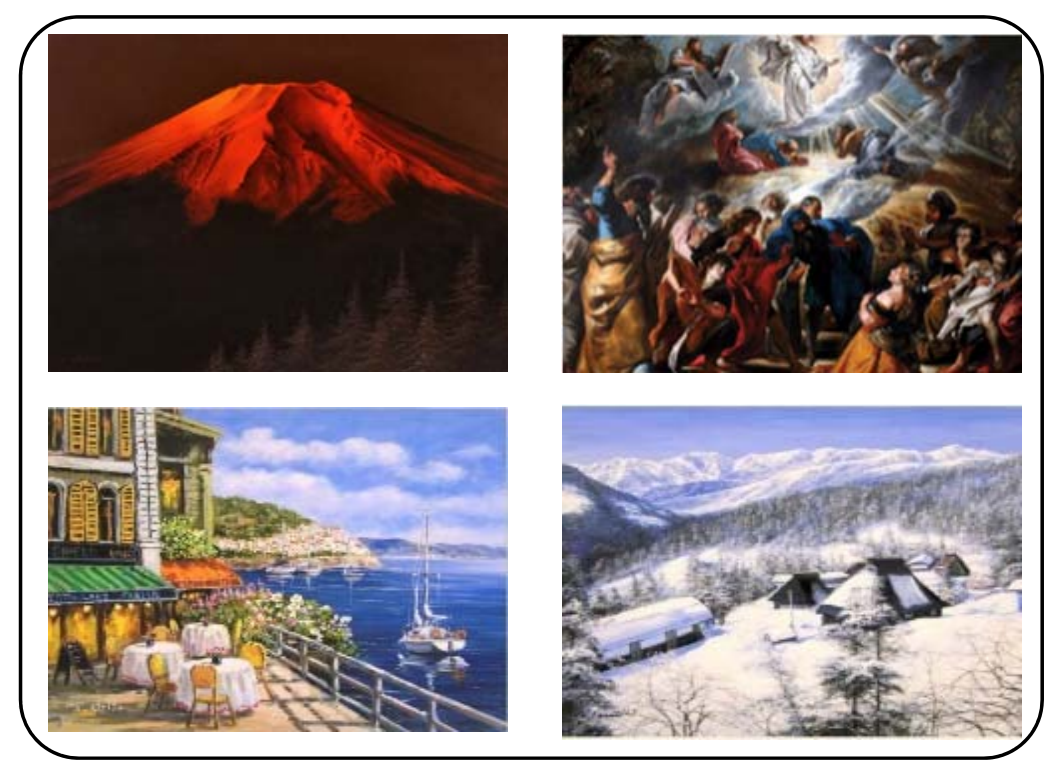

Figure 3 -Painting A (upper left), Painting B (upper right), Painting C (lower left), Painting D (lower left) 
A LED spotlight (blue-phosphor white LEDs, Ra: 97, CCT: $3000 \mathrm{~K}$, duv: -0.005 ) had a trimming function to squarely illuminate the painting. Ambient lightings (purple-phosphor white LEDs, Ra > 93, СCT: $3000 \mathrm{~K}$, duv $< \pm 0.005$ ) were installed in the high-sidelight position.

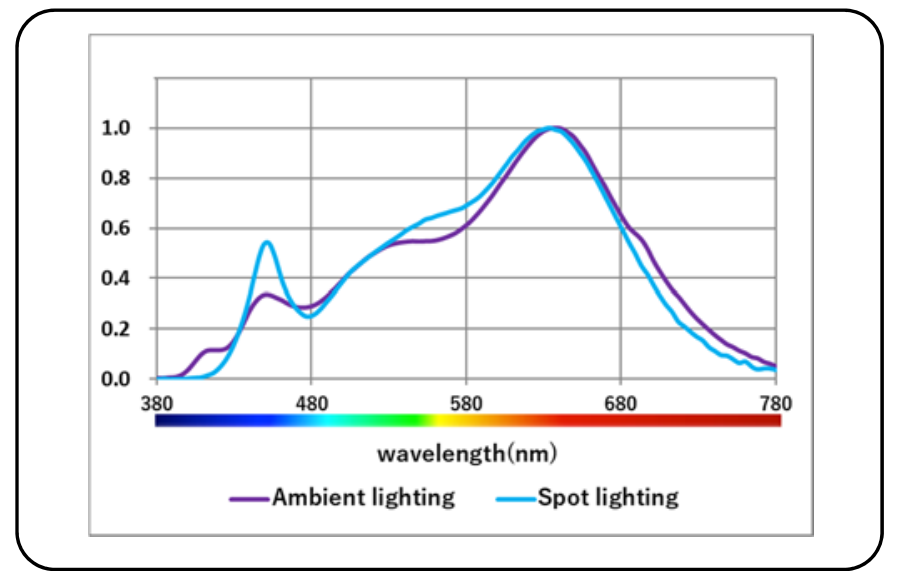

Figure 4 - Relative spectral power distribution

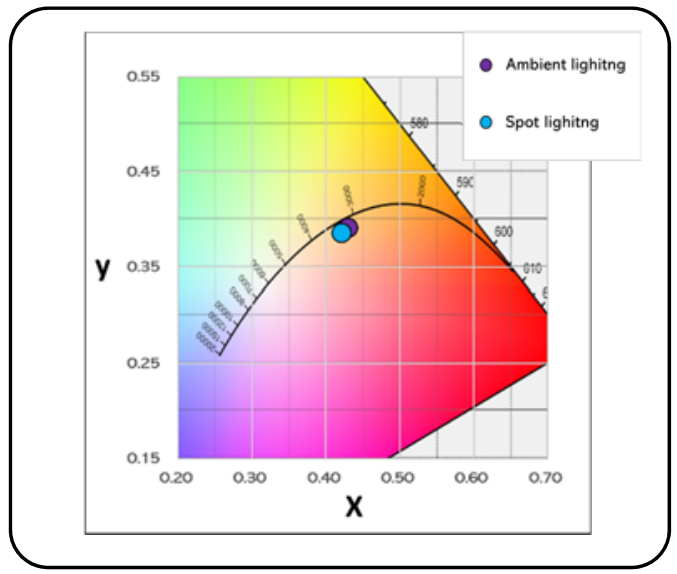

Figure 5 - Chromaticity diagram

Illuminance on the painting had three levels (200 lux, $100 \mathrm{lux}, 50 \mathrm{lux}$ ) and luminance ratio was set to be ten levels $(1 / 3,1 / 1.5,1,1.5,3,4.5,6,10,12.5,15)$ by dimming the LED spotlight and the ambient lighting. There were 159 experimental conditions as shown in Table1 in all.

\section{Table 1 - Experimental Conditions}

\begin{tabular}{|c|c|c|c|c|c|c|c|c|c|c|c|c|}
\hline \multirow{2}{*}{$\begin{array}{c}\text { Wall } \\
\text { (Reflectance) }\end{array}$} & \multirow{2}{*}{$\begin{array}{c}\text { Painting } \\
\text { (Reflectance) }\end{array}$} & \multirow{2}{*}{$\begin{array}{l}\text { Illuminance of } \\
\text { Painting }\end{array}$} & \multicolumn{10}{|c|}{ Luminance ratio } \\
\hline & & & $1 / 3$ & $1 / 1.5$ & 1 & 1.5 & 3 & 4.5 & 6 & 10 & 12.5 & 15 \\
\hline \multirow{12}{*}{$\begin{array}{c}\text { N2 } \\
(3.1 \%)\end{array}$} & \multirow{3}{*}{$\begin{array}{c}A \\
(7.3 \%)\end{array}$} & $501 x$ & & & & & & 0 & 0 & 0 & & \\
\hline & & $100 \mid x$ & & & & & 0 & 0 & 0 & 0 & & \\
\hline & & $2001 x$ & & & & & 0 & 0 & 0 & 0 & & \\
\hline & \multirow{3}{*}{$\begin{array}{c}\text { B } \\
(15.7 \%)\end{array}$} & $501 x$ & & & & & & 0 & 0 & 0 & 0 & 0 \\
\hline & & $1001 x$ & & & & & & 0 & 0 & 0 & 0 & 0 \\
\hline & & $2001 x$ & & & & & & 0 & 0 & 0 & 0 & 0 \\
\hline & \multirow{3}{*}{$\begin{array}{c}\text { C } \\
(26.7 \%)\end{array}$} & $501 x$ & & & & & & & & 0 & 0 & 0 \\
\hline & & $100 / x$ & & & & & & & & 0 & 0 & 0 \\
\hline & & $2001 x$ & & & & & & & & 0 & 0 & 0 \\
\hline & \multirow{3}{*}{$\begin{array}{c}\text { D } \\
(37.2 \%)\end{array}$} & $501 x$ & & & & & & & & & & \\
\hline & & $1001 x$ & & & & & & & & & & \\
\hline & & $2001 x$ & & & & & & & & & & \\
\hline \multirow{12}{*}{$\begin{array}{c}\text { N5 } \\
(19.8 \%)\end{array}$} & \multirow{3}{*}{$\begin{array}{c}A \\
(7.3 \%)\end{array}$} & $501 x$ & & 0 & 0 & 0 & 0 & & & & & \\
\hline & & $1001 x$ & & 0 & 0 & 0 & 0 & 0 & 0 & & & \\
\hline & & $2001 x$ & & 0 & 0 & 0 & 0 & 0 & 0 & 0 & & \\
\hline & \multirow{3}{*}{$\begin{array}{c}\text { B } \\
(15.7 \%)\end{array}$} & $501 x$ & & & 0 & 0 & 0 & 0 & 0 & 0 & & \\
\hline & & $1001 x$ & & & 0 & O & 0 & 0 & O & 0 & & \\
\hline & & $2001 x$ & & & 0 & 0 & 0 & 0 & 0 & 0 & & \\
\hline & \multirow{3}{*}{$\begin{array}{c}\text { C } \\
(26.7 \%)\end{array}$} & $501 x$ & & & & 0 & 0 & 0 & 0 & 0 & & \\
\hline & & $1001 x$ & & & & 0 & 0 & 0 & 0 & 0 & & \\
\hline & & $2001 x$ & & & & & 0 & 0 & 0 & 0 & & \\
\hline & \multirow{3}{*}{$\begin{array}{c}\text { D } \\
(37.2 \%)\end{array}$} & $501 x$ & & & & & 0 & 0 & 0 & 0 & & \\
\hline & & $1001 x$ & & & & & 0 & 0 & 0 & 0 & & \\
\hline & & $2001 x$ & & & & & 0 & 0 & 0 & 0 & & \\
\hline \multirow{12}{*}{$\begin{array}{c}\text { N8 } \\
(59.1 \%)\end{array}$} & \multirow{3}{*}{$\begin{array}{c}\text { A } \\
(7.3 \%)\end{array}$} & $501 x$ & 0 & 0 & 0 & & & & & & & \\
\hline & & $1001 x$ & 0 & 0 & 0 & 0 & 0 & & & & & \\
\hline & & $2001 x$ & 0 & 0 & 0 & 0 & 0 & & & & & \\
\hline & \multirow{3}{*}{$\begin{array}{c}\text { B } \\
(15.7 \%)\end{array}$} & $501 x$ & & & 0 & 0 & 0 & 0 & & & & \\
\hline & & $100 \mid x$ & & & 0 & 0 & 0 & 0 & & & & \\
\hline & & $2001 x$ & & & 0 & 0 & 0 & 0 & 0 & 0 & & \\
\hline & \multirow{3}{*}{$\begin{array}{c}\text { C } \\
(26.7 \%)\end{array}$} & $501 x$ & & & 0 & 0 & 0 & 0 & 0 & 0 & & \\
\hline & & $1001 x$ & & & 0 & 0 & 0 & 0 & 0 & 0 & & \\
\hline & & $2001 x$ & & & 0 & 0 & 0 & 0 & 0 & 0 & & \\
\hline & \multirow{3}{*}{$\begin{array}{c}\text { D } \\
(37.2 \%)\end{array}$} & $501 x$ & & & 0 & 0 & 0 & 0 & 0 & 0 & & \\
\hline & & $1001 x$ & & & 0 & 0 & 0 & 0 & 0 & 0 & & \\
\hline & & $2001 x$ & & & 0 & 0 & 0 & 0 & 0 & 0 & & \\
\hline
\end{tabular}


25 university students, aged 21-25 with normal colour vision, participated the experiment. Subjects evaluated the appearance of the painting and the preference for the luminance ratio with 9-point bipolar scales such as "-4: Not preferable" to "4: Preferable".

Table 2 - Evaluation

\begin{tabular}{|ccc|}
\hline \multicolumn{4}{|c|}{ Entire evaluation for the appearance of the paintings } \\
\hline & Evaluation scales $(\mathbf{- 4 \sim + 4 )}$ & \\
\hline Dazzling & - & Not dazzling \\
\hline Dark & - & Bright \\
\hline Difficult detail discrimination & - & Easy detail discrimination \\
\hline Invisible brush touch & - & Visible brush touch \\
\hline Fuzzy outline & - & Clear outline \\
\hline Not having a sense of space & - & Having a sense of space \\
\hline Drab & - & Colourful \\
\hline Unnatural & - & Natural \\
\hline Difficult to see & - & Easy to see \\
\hline Not preferable & - & Preferable \\
\hline
\end{tabular}

The procedure of the experiment was as follows; first, the subject adjusted for 10 minutes to the experimental room whose illuminance and CCT on the painting was 50lx and $3000 \mathrm{~K}$, respectively. Next, the experimenter set the lighting condition, then the subject observed the painting for 30 seconds and evaluated it in 2 minutes. After the subject finished evaluating, the experimenter set the next lighting condition. Lighting conditions were presented in random order for each participant.

\section{Results}

\subsection{Factor analysis}

We conducted factor analysis to clarify the evaluation scales. As a result, as is the case of previous research (Loe, D. L.1982), two factors were obtained, and Factor 1 included "Preferable", "Natural", "Colourful" and "Easy to see" and was named "Quality Evaluation Factor", whereas Factor 2 had "Clear outline", "Visible brush touch" and "Easy details discrimination" and was named "Discrimination Factor".

Table 3 - Factor Loading

\begin{tabular}{|c|r|r|}
\hline Evaluation scales & $\begin{array}{c}\text { Factor 1 } \\
\text { Quality } \\
\text { Evaluation }\end{array}$ & $\begin{array}{c}\text { Factor 2 } \\
\text { Discrimination }\end{array}$ \\
\hline Dazzling /Not dazzling & -0.027 & -0.126 \\
\hline Dark/Bright & 0.448 & 0.551 \\
\hline Difficult detail discrimination/Easy detail discrimination & 0.535 & 0.721 \\
\hline Invisible brush touch/Visible brush touch & 0.444 & 0.755 \\
\hline Fuzzy outline/Clear outline & 0.487 & 0.781 \\
\hline Not having a sense of space/Having a sense of space & 0.679 & 0.445 \\
\hline Drab/Colourful & 0.658 & 0.575 \\
\hline Unnatural/Natural & 0.825 & 0.340 \\
\hline Difficult to see/Easy to see & 0.826 & 0.369 \\
\hline Not preferable/Preferable & 0.867 & 0.294 \\
\hline
\end{tabular}




\subsection{Multiple regression analysis}

We conducted multiple regression analysis to examine the relationship between visual evaluation of paintings and physical values measured in each experimental condition. The objective variables were synthesis variables of Factor 1 and Factor 2. Each factor included evaluation scales whose factor loading was more than 0.6. Resulting from the examination of various explanatory variables, the equations with relatively high coefficients of determination are as shown below.

Estimation equation of "Quality Evaluation Factor":

$$
Y=-2.58+0.66 \log X_{1}+0.58 \log X_{2}-0.14 X_{3}+0.15 X_{4}
$$

Estimation equation of "Discrimination Factor":

$$
Y^{\prime}=-2.71+0.63 \log X_{1}+0.67 \log X_{2}-0.13 X_{3}+0.15 X_{4}
$$

where

$Y \quad$ is the value of synthesis variables of Factor 1;

$Y$, is the value of synthesis variables of Factor 2;

$X_{1} \quad$ is luminance ratio (painting luminance/surrounding luminace)

$X_{2} \quad$ is Illuminance on the painting

$X_{3} \quad$ is lightness of the painting

$X_{4} \quad$ is lightness of the wall surface
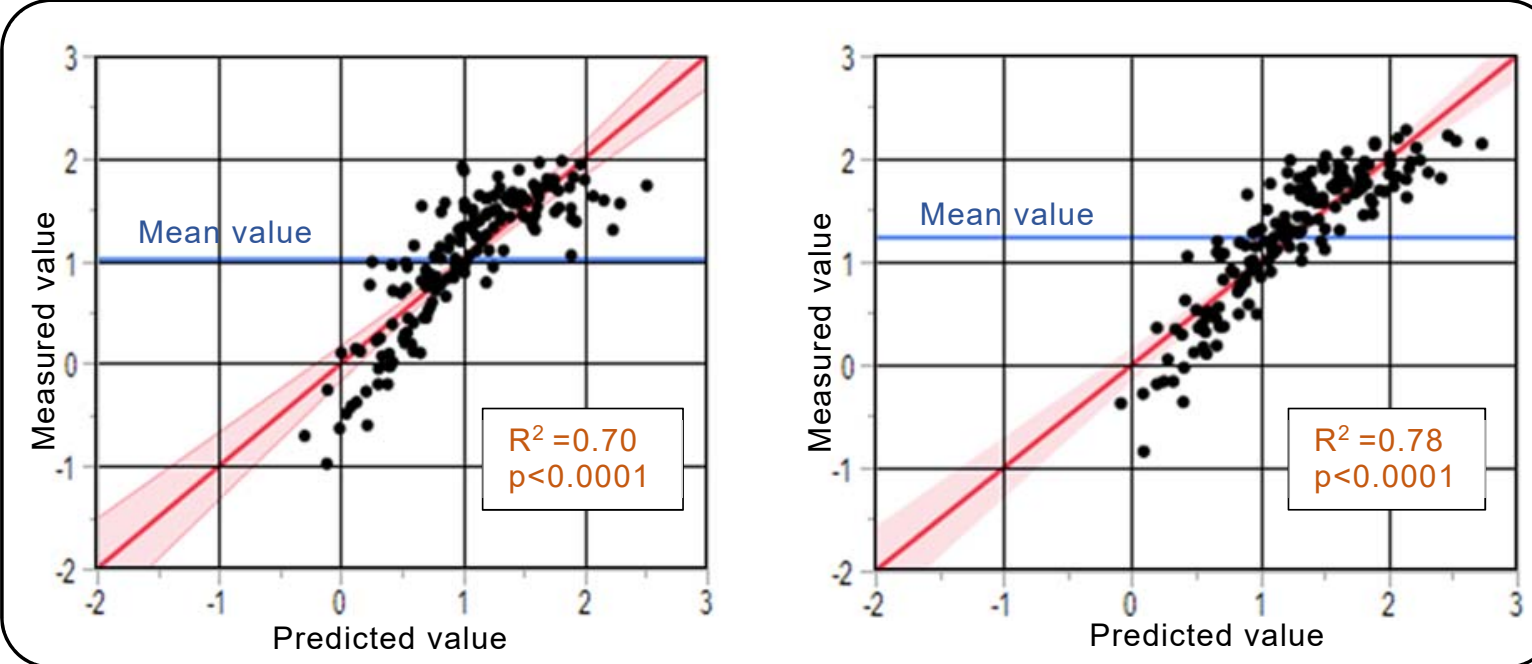

Figure 6 - Plots of predicted and measured values of Factor 1 (left), Factor 2 (right)

Factors 1 and 2 was both predicted by luminance ratio, illuminance on the painting, lightness of the painting and lightness of the wall surface. It showed that the higher the luminance ratio and the higher the illuminance on the painting becomes, the higher the evaluation is, while the lower the lightness of the painting and the higher the lightness of the wall surface becomes, the higher the evaluation is.

\subsection{Preference of the paintings}

Figure 7, 8, and 9 shows average evaluation values and fitted curves of the preference of paintings which had the highest factor load in Factor 1 . The higher the luminance ratio is, the smaller the difference in the evaluation of each illuminance on the painting becomes.

When the background lightness was N8, 100 Ix was enough illuminance on the painting for the painting $A$ (reflectance: $7.3 \%$ ) because the appearance of the painting under $1001 x$ was always 
preferable to $2001 x$. For painting B (reflectance: $15.7 \%$ ) the preference of the appearance under the painting illuminance of $100 \mathrm{~lx}$ reached to the preference under $200 \mathrm{~lx}$ when the luminance ratio was about 3 . For painting $C$ (reflectance: $26.7 \%$ ), the preference under $1001 x$ got close to $2001 x$ at the luminance ratio 6 , and for painting $D$ (reflectance: $37.2 \%$ ), the luminance ratio 7 was necessary to have the same preference between 100lx and 200lx.

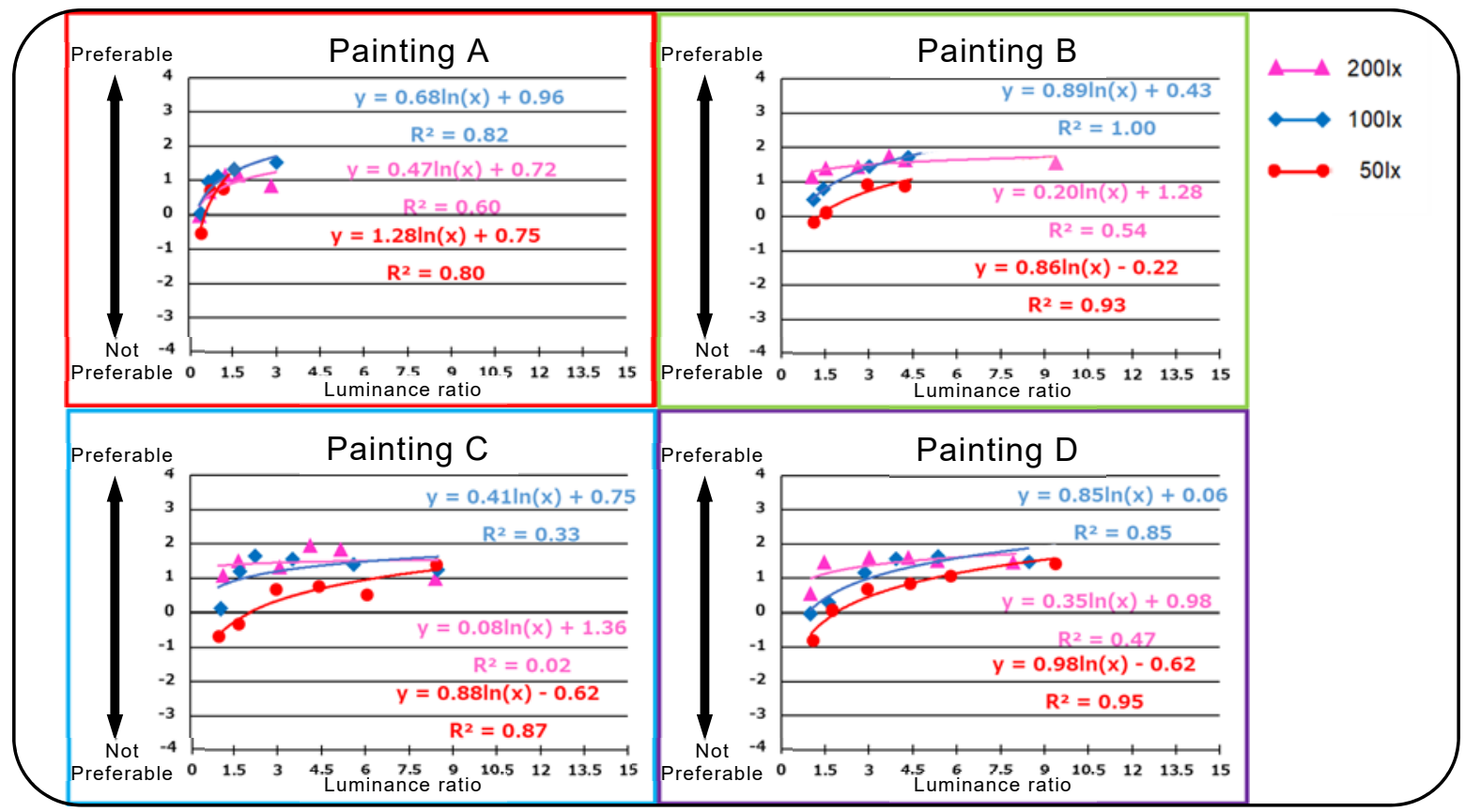

Figure 7 - Preference of the paintings on N8 background

When the background lightness was N5, the appearance of the painting $A$ under 100lx was again always preferable. For painting $B$, the preference of the appearance under the painting illuminance of $100 \mathrm{~lx}$ reached to the preference under $200 \mathrm{~lx}$ when the luminance ratio was about 5 . For painting $C$, the preference under $1001 x$ got close to $2001 x$ at the luminance ratio below 5 , and for painting $D$, the luminance ratio over 7 was necessary to have the same preference between $1001 x$ and $2001 x$.

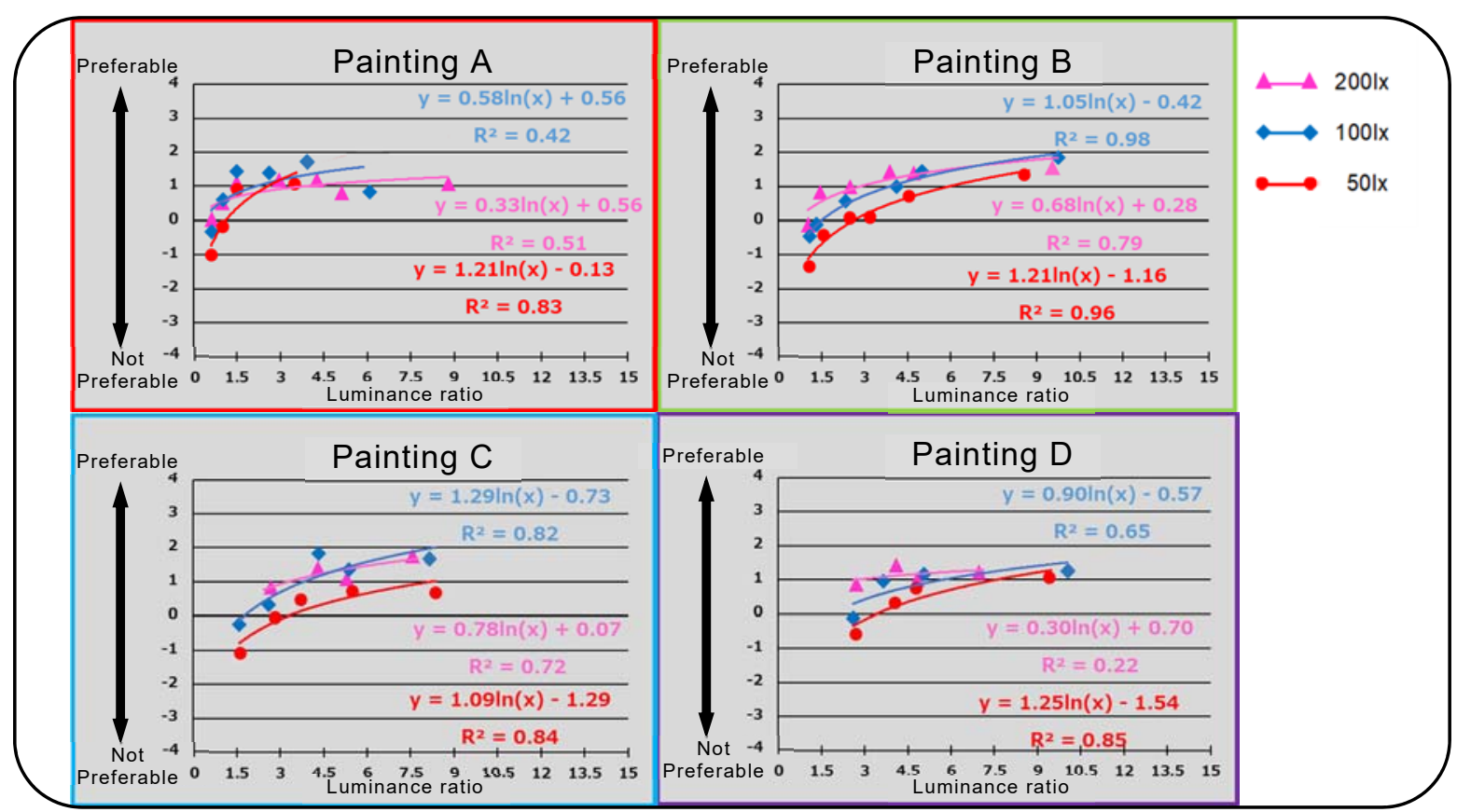

Figure 8 - Preference of the paintings on N5 background 
When the background lightness was N2, as to painting A, 100lx condition was evaluated higher than $2001 x$ when the luminance ratio became about 3.5 or higher, and 50lx condition was evaluated higher than $2001 x$ when the luminance ratio became about 6.5 or higher. As to painting B, 100lx condition was evaluated higher than $2001 x$ when the luminance ratio became about 11 or higher. As to painting $C$, the evaluation of $2001 x$ condition was always higher than other illuminance conditions, however, the difference from the evaluation of 100 lx was small.

There results indicated that in the most settings the appearance of the paintings was preferred even though the painting illuminance was only $100 \mathrm{~lx}$, provided that the luminance ratio was sufficiently high.

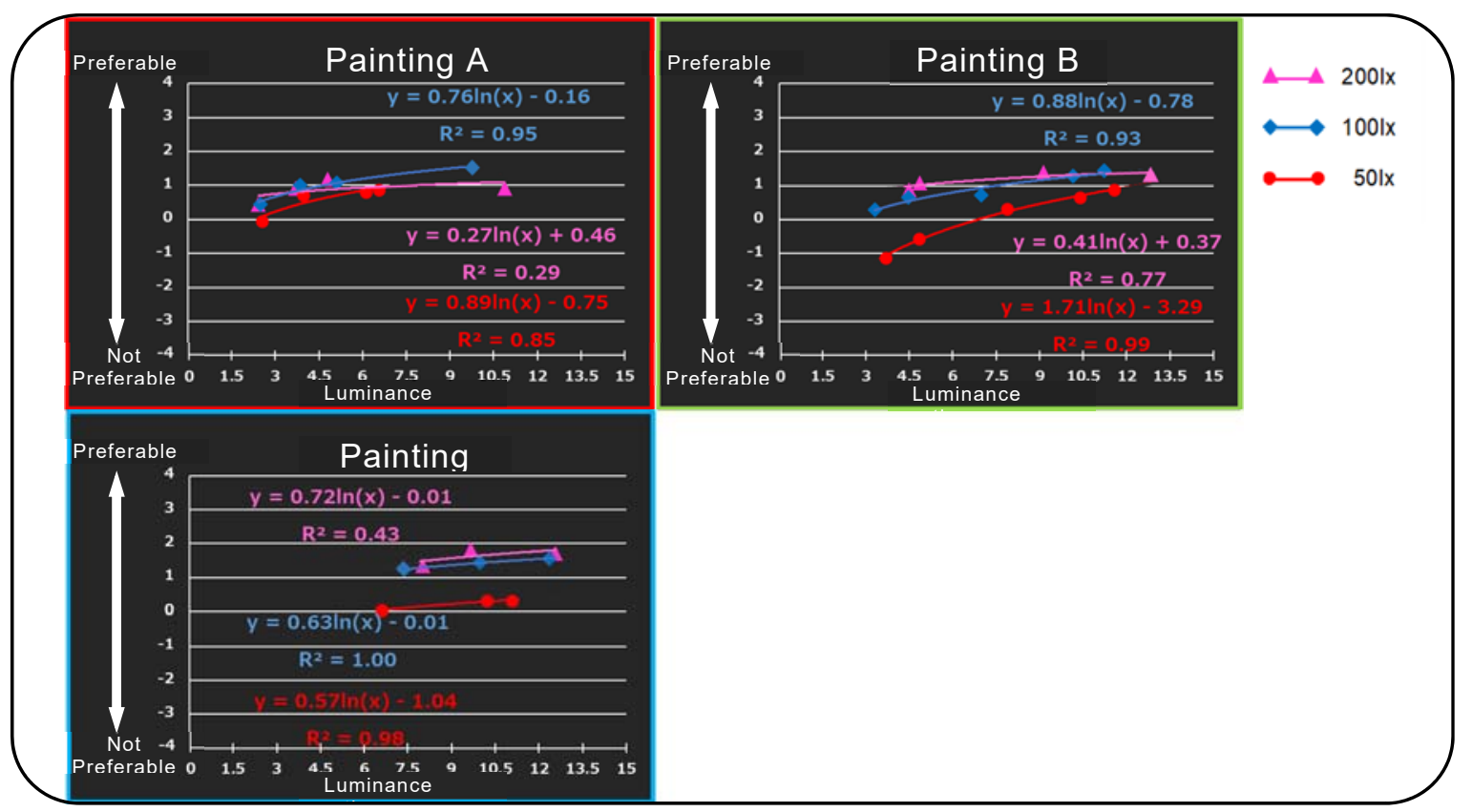

Figure 9 - Preference of the paintings on N2 background

\subsection{Clear appearance of paintings}

Figure 10, 11 and 12 shows average evaluation values and fitted curves of the clear appearance of paintings which was the highest factor load in Factor 2.

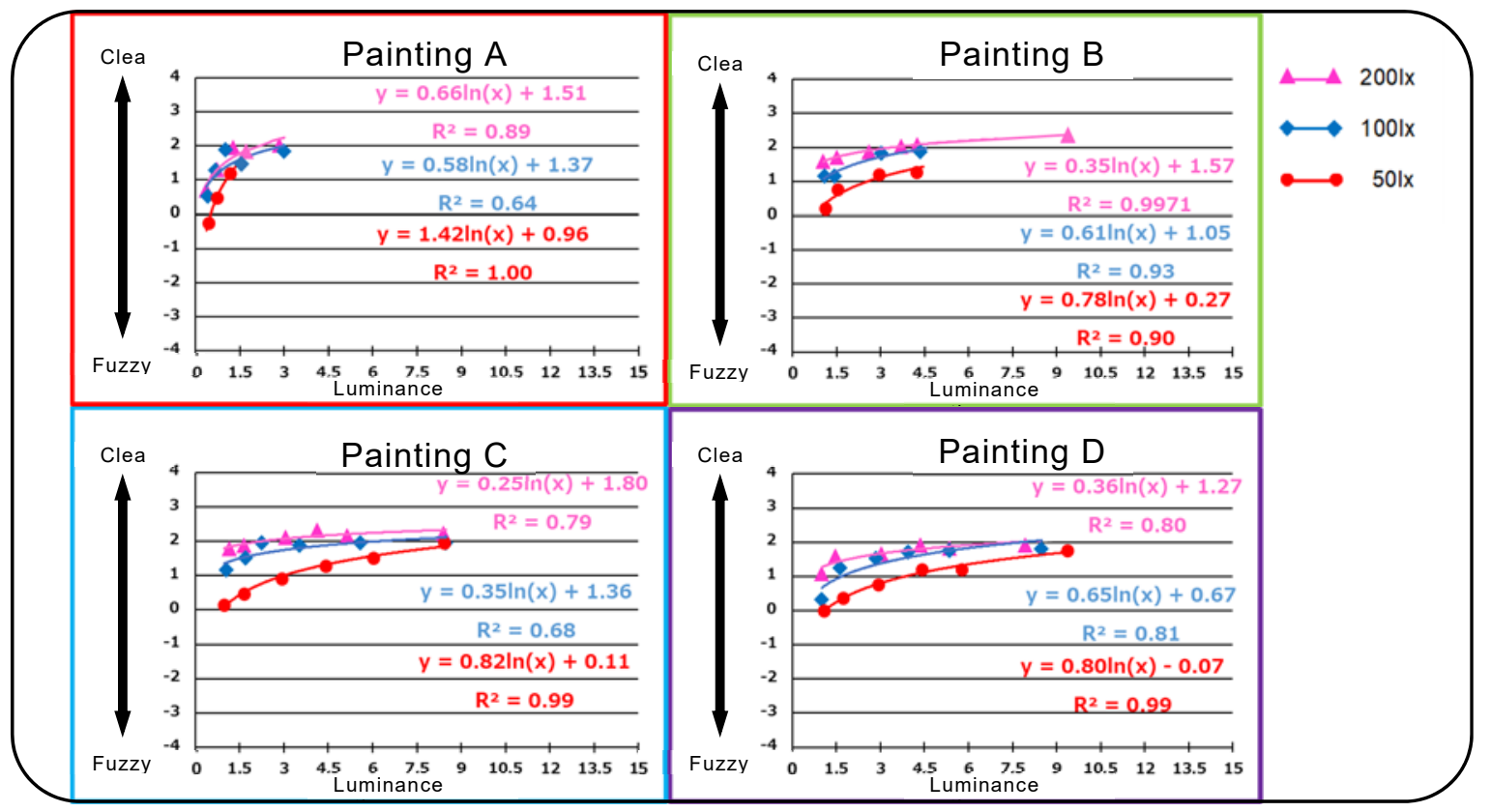

Figure 10 - Clear outline of paintings on N8 background 
When the background lightness was N8 and N5, there was a tendency that the higher the luminance ratio was, the smaller the difference in the evaluation of the paintings became among various conditions of illuminance on the paintings, however, the paintings under the illuminance of $2001 x$ looked always clear despite of the luminance ratio.

When the background lightness was N2, paintings with illuminance 200lx were always highly evaluated in clear appearances.

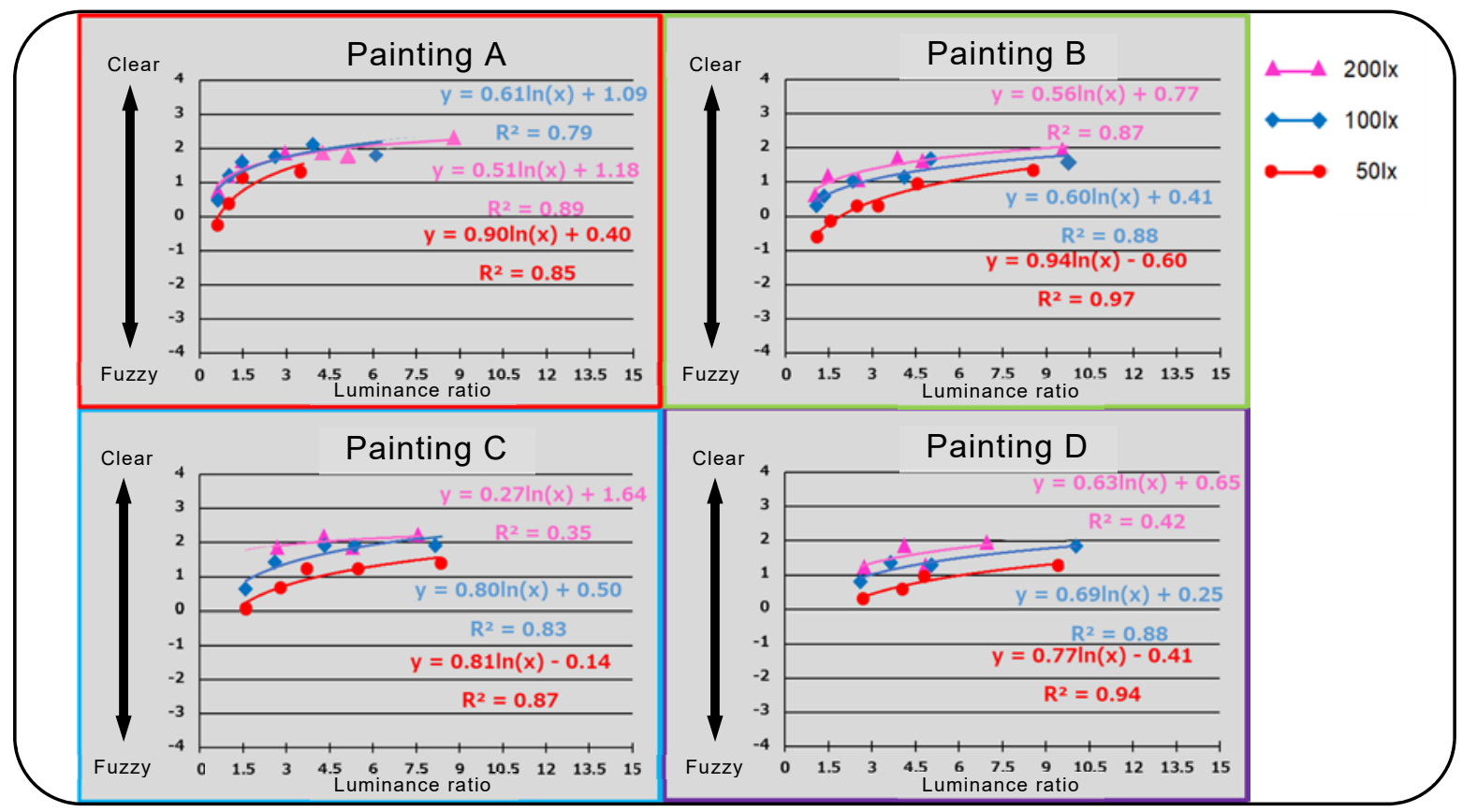

Figure 11 - Clear outline of paintings on N5 background

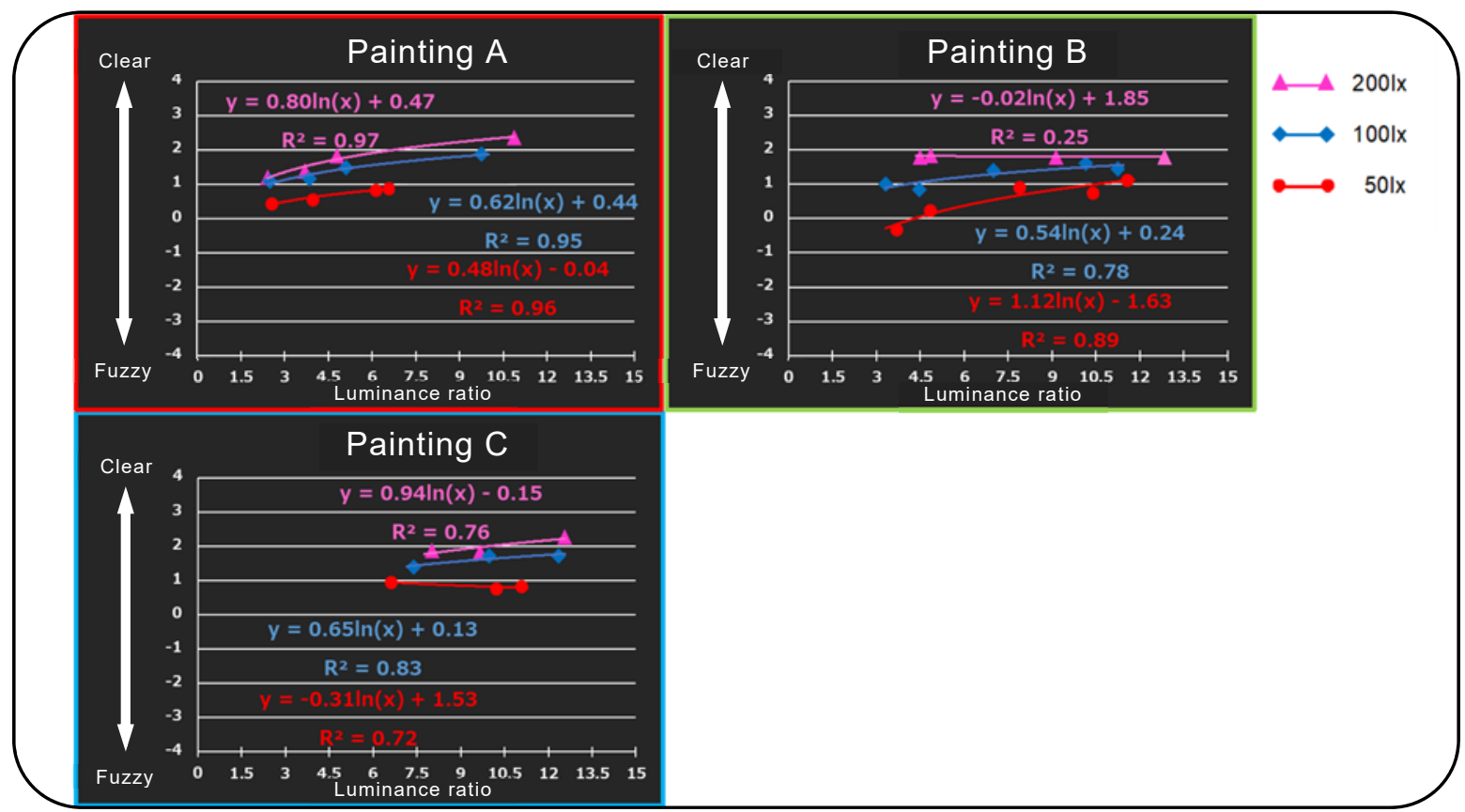

Figure 12 - Clear outline of paintings on N2 background 


\section{Conclusions}

The results of the subjective experiment showed that Quality Evaluation Factor could be ensured even though the illuminance on the paintings were $1001 x$, provided that the luminance ratio was sufficiently high, whereas Discrimination Factor was always highly evaluated when the painting illuminance was $2001 x$. In this paper, we did not clarify the quantitative values for required luminance ratio to acquire the preferable appearance for the paintings, however, by continuing to accumulate data on various paintings and settings, we could get some useful luminance-based guidelines for museums.

\section{Acknowledgments}

We are grateful to CCS.inc for providing the lighting equipment used in this research.

\section{References}

Loe, D. L. and Rowlands, E. 1982. Preferred lighting conditions for the display of oil and watercolour paintings. Lighting Res. Technol., 14, 173-192.

CHRISTOPHER, C. 2007. Light for Art's Sake: Butterworth-Heinemann.

CHRISTOPHER, C. 2007. LIGHTING BY DESIGN: Architectural Press.

CIE 2004. CIE 157:2004. Control of damage to museum objects by optical radiation. Vienna 